\title{
Introduction
}

\section{Anti-inflammatory treatment of childhood asthma: cromoglycate and nedocromil as non-steroidal alternatives?}

Since asthma has been recognized as a chronic inflammatory disorder of the airways, anti-inflammatory drugs and, in particular, corticosteroids have become first-line treatment. ${ }^{1,2}$ Concern remains on the potential side-effects of inhaled corticosteroids especially in children. ${ }^{3}$ Inhaled steroids have an excellent safety profile, and are widely used in paediatric asthma treatment. ${ }^{4}$ Their long-term use in young children is generally thought to be both safe and effective, but small systemic effects can be demonstrated even with moderate doses. ${ }^{5,6}$ These effects include the short-term inhibition of growth of long bones, and the suppression of basal cortisol secretion levels. Apart from these, there are risks of local side-effects including hoarseness and thrush. It is, however, generally felt that the benefits of steroids in asthmatic children greatly outweigh the small potential risks.

Despite the low toxicity of inhaled steroids, the availability of non-steroidal anti-inflammatory medication for treating asthmatic children is highly desirable because of the relatively high numbers of asthmatic children requiring maintenance treatment, and the long duration of anti-inflammatory asthma treatment. Two effective non-steroidal anti-asthma drugs with anti-inflammatory activities are presently available: cromoglycate and nedocromil. Of these cromoglycate has been used for many years and has proven to be both effective and extremely safe. Cromoglycate has been advocated as a first-choice drug for moderate paediatric asthma where maintenance treatment is required. ${ }^{1}$ Much less data are available on nedocromil, a novel pyranoquinoline dicarboxylic acid with a broad spectrum of antiinflammatory actions. ${ }^{7}$ Nedocromil is more potent than cromoglycate, but it has been difficult to prove its superiority to cromoglycate in vivo. ${ }^{8}$ Data on the effect of nedocromil in children with asthma are scanty, and tend to confirm its effectiveness in mod- erate asthma. The data presently available do not permit a clear positioning of the drug in clinical paediatric practice. Because nedocromil is one of the few drugs without steroid side-effects which can be applied in childhood asthma, and because it has antiinflammatory effects, it deserves thorough study.

The present supplement issue of Mediators of Inflammation contains a selection of papers and abstracts on cromoglycate and nedocromil in childhood asthma from a recent symposium, where both clinical and laboratory studies on nedocromil were reported in order to get a better understanding of their mechanisms of action, especially in children. The editors think that publishing these original data may help in the further positioning of these drugs in the treatment of childhood asthma, an important and increasing disease with a major impact on childhood health.

Johan C. de Jongste

Department of Paediatrics, Division of Paediatric Respiratory Medicine, Erasmus University and University Hospital/ Sophia Children's Hospital,

Dr. Molewaterplein 60, 3015 GJ Rotterdam, The Netherlands

\section{References}

1. Warner JO. Asthma: a follow-up statement from an international pediatric asthma consensus group. Arch Dis Cbildhood 1992; 67: 240-248.

2. Barnes PJ, Pedersen S. Efficacy and safety of inhaled corticosteroids in asthma. Am Rev Respir Dis 1993; 148: S1-S26.

3. Kamada AK, Parks DP, Szefler SJ. Inhaled glucocorticoid therapy in children: how much is safe? Pediatric Pulmonol 1992; 12: 71-72.

4. Kerrebijn KF. Use of topical corticosteroids in the treatment of childhood asthma Am Rev Respir Dis 1990; 141: S77-S81.

5. Pedersen S. Safety aspects of corticosteroids in children. Eur Respir Rev 1994; 4 $33-43$

6. König P. The risks and benefits of inhaled corticosteroids. Eur Respir Rev 1993; 3 $15,501-510$

7. Thomson N. Nedocromil sodium: an overview. Respir Med 1989: 83: 269-276.

8. Edwards AM, Stevens MT. The clinical efficacy of inhaled nedocromil sodium (Tilade) in the treatment of asthma. Eur Respir J 1993; 6: 35-41. 


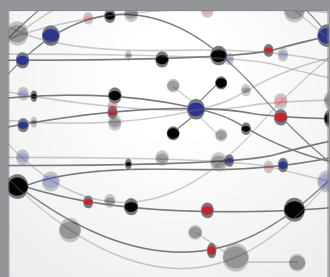

The Scientific World Journal
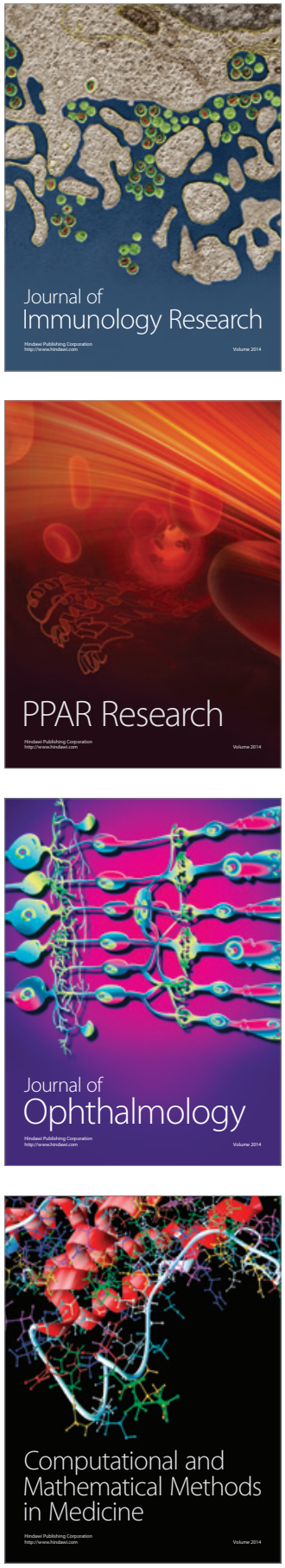

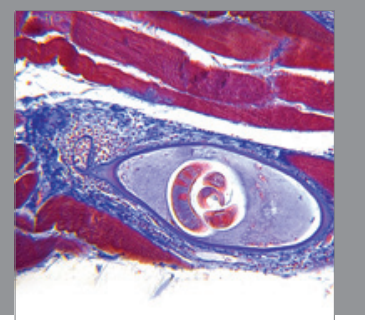

Gastroenterology

Research and Practice
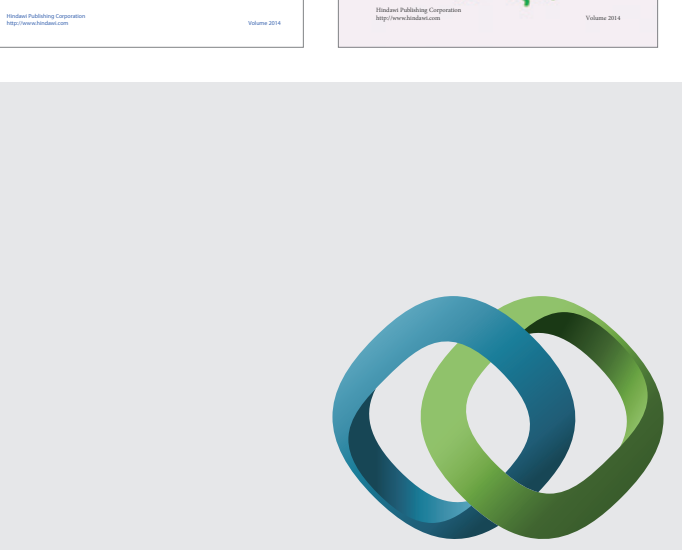

\section{Hindawi}

Submit your manuscripts at

http://www.hindawi.com
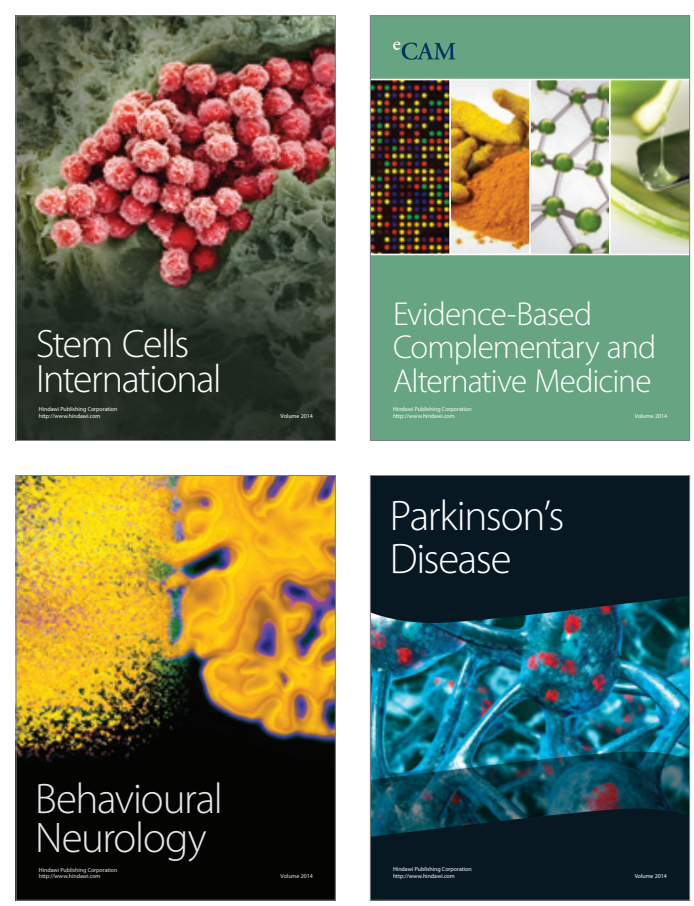

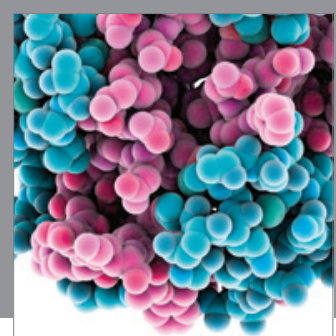

Journal of
Diabetes Research

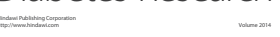

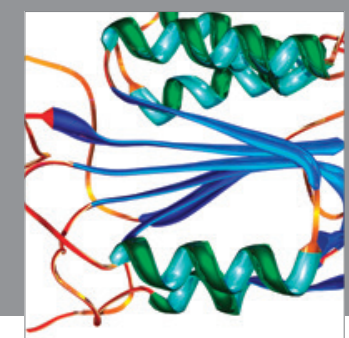

Disease Markers
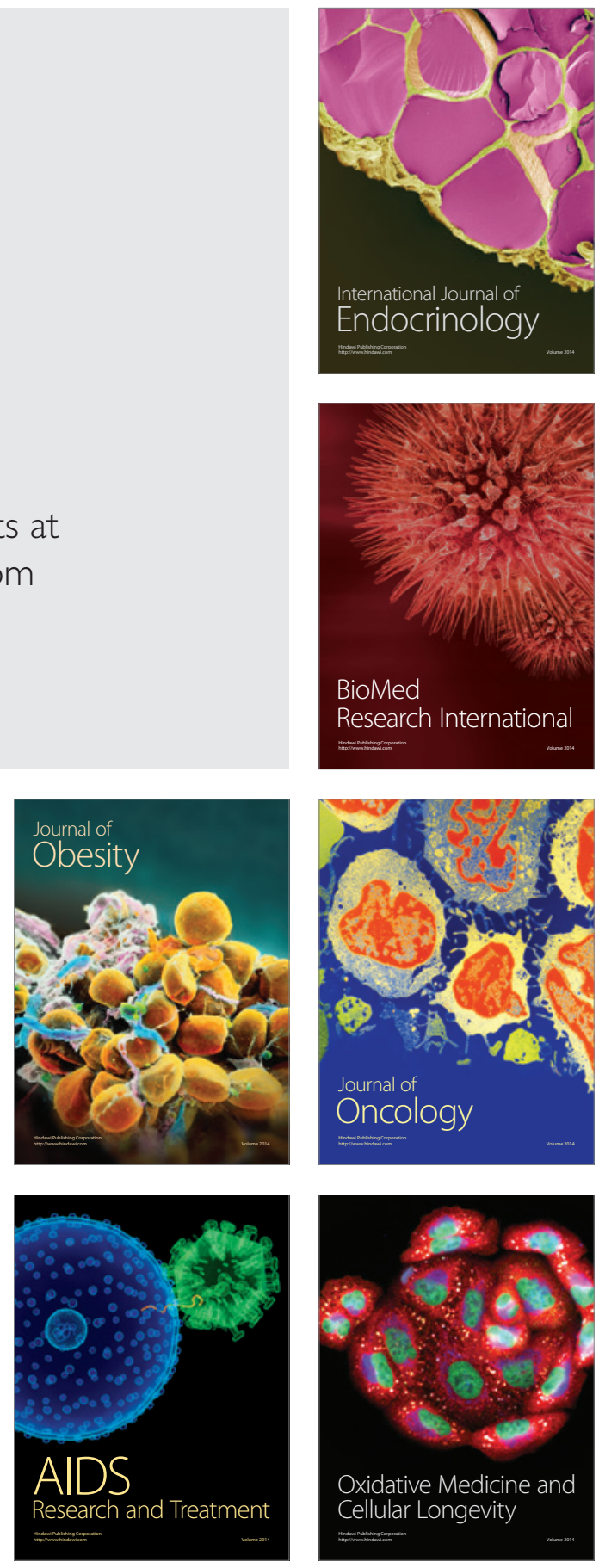